\title{
Coexistence of partial anomalous pulmonary venous return and cardiac coronary anomaly - the role of preoperative imaging
}

\author{
Mikołaj Frankiewicz ${ }^{1}$, Tomasz Marjański², Grzegorz Łaskawski \\ ${ }^{1}$ University Clinical Centre, Gdansk, Poland \\ ${ }^{2}$ Department of Thoracic Surgery, Medical University of Gdansk, Poland \\ ${ }^{3}$ Clinic of Cardiac and Vascular Surgery, University Clinical Centre, Gdansk, Poland
}

Kardiochirurgia i Torakochirugia Polska 2017; 14 (2): 141-142

Typical vascular patterns of upper pulmonary lobes are observed in $48 \%$ of individuals on the right side and in $46 \%$ on the left side [1, 2]. Historically, preoperative imaging of the pulmonary vessels required pulmonary angiography, which was an invasive procedure with limited indications. Nowadays, routine chest computed tomography (CT) provides sufficient imaging of pulmonary arteries and veins. We observed an unusual coincidence of anomalies in pulmonary and coronary vessels in a patient with non-small cell lung cancer (NSCLC). Due to preoperative imaging with $\mathrm{CT}$ angiography and classical coronary catheterization it was possible to provide uncomplicated treatment. Anomalous pulmonary venous connections are a specific group of congenital heart defects caused by the abnormal drainage of a part or the entire lung to a systemic vein or the right atrium. The estimated incidence is $2 / 100000$ births [3].

Prevalence of coronary anomalies is estimated to be $0.2 \%$ to $1.3 \%$ of patients undergoing coronary angiography [4]. Coexistence of both is very rarely, if ever, described. In

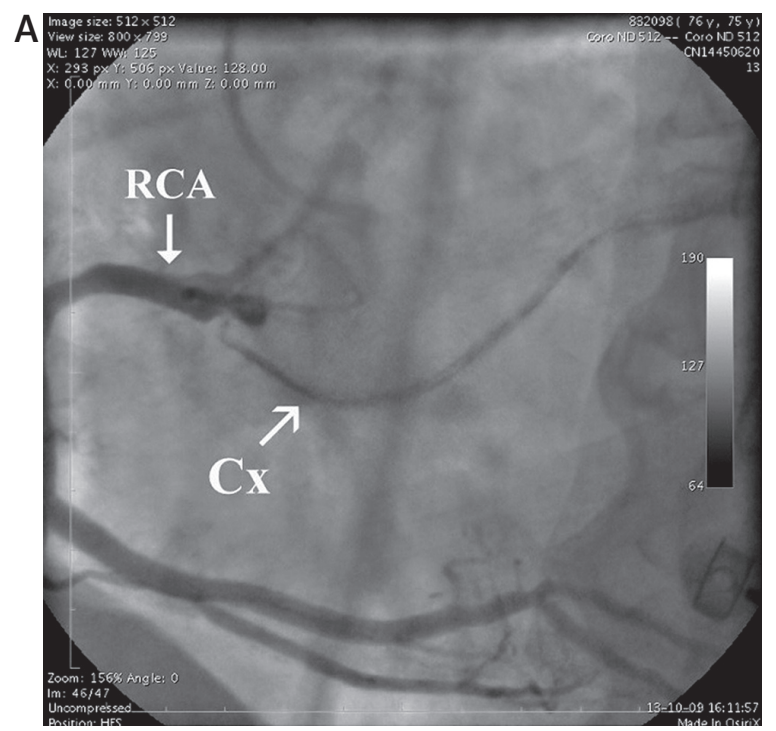

most cases (80-90\%) partial anomalous pulmonary venous return (PAPVR) is combined with an atrial septal defect $[5,6]$. We report a case of anomalous right upper lobe venous drainage to the vena cava superior and to the left atrium with coexisting cardiac coronary anomaly diagnosed in classical coronary catheterization and consisting of the circumflex coronary artery originating from the right rather than the left coronary artery.

A 75-year-old man was admitted to the hospital due to a tumor of the right lung confirmed to be NSCLC. The only symptom was a non-productive cough. The lesion was detected during a routine follow-up after nephrectomy due to early papillary renal cell carcinoma 6 years ago. It was a solid focal lesion with slightly irregular borders, measuring $16 \times 13 \mathrm{~mm}$. Preoperative evaluation revealed coronary artery disease that required a coronary artery bypass. Preoperative coronary catheterization showed an anomalous right-sided variation of the circumflex coronary artery (Fig. $1 \mathrm{~A}, \mathrm{CX}$ ). Off pump coronary artery bypass (OPCAB)

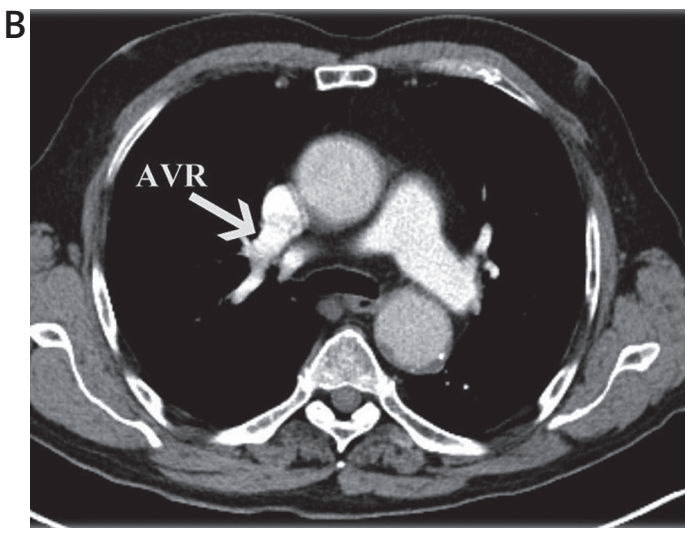

Fig. 1. A - Preoperative coronary catheterization showing an anomalous circumflex coronary artery $(\mathrm{Cx})$ originating from the right coronary artery (RCA). B - Anomalous venous return of the superior lobe of the right lung - a vein (AVR) measuring $15 \mathrm{~mm}$ in diameter draining to the vena cava superior

Address for correspondence: Mikołaj Frankiewicz MD, University Clinical Centre, 80-214 Gdansk, Poland, phone: +48 583493154 , e-mail: mfrankiewicz@gumed.edu.pl

Received: 12.07.2016, accepted: 14.02.2017. 


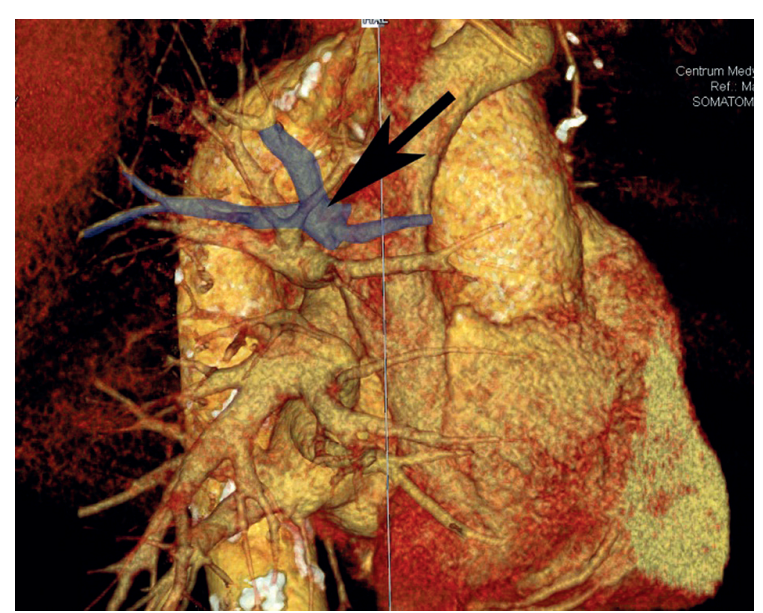

Fig. 2. Anomalous venous return of the superior lobe of the right lung - a vein (AVR) measuring $15 \mathrm{~mm}$ in diameter draining to the vena cava superior
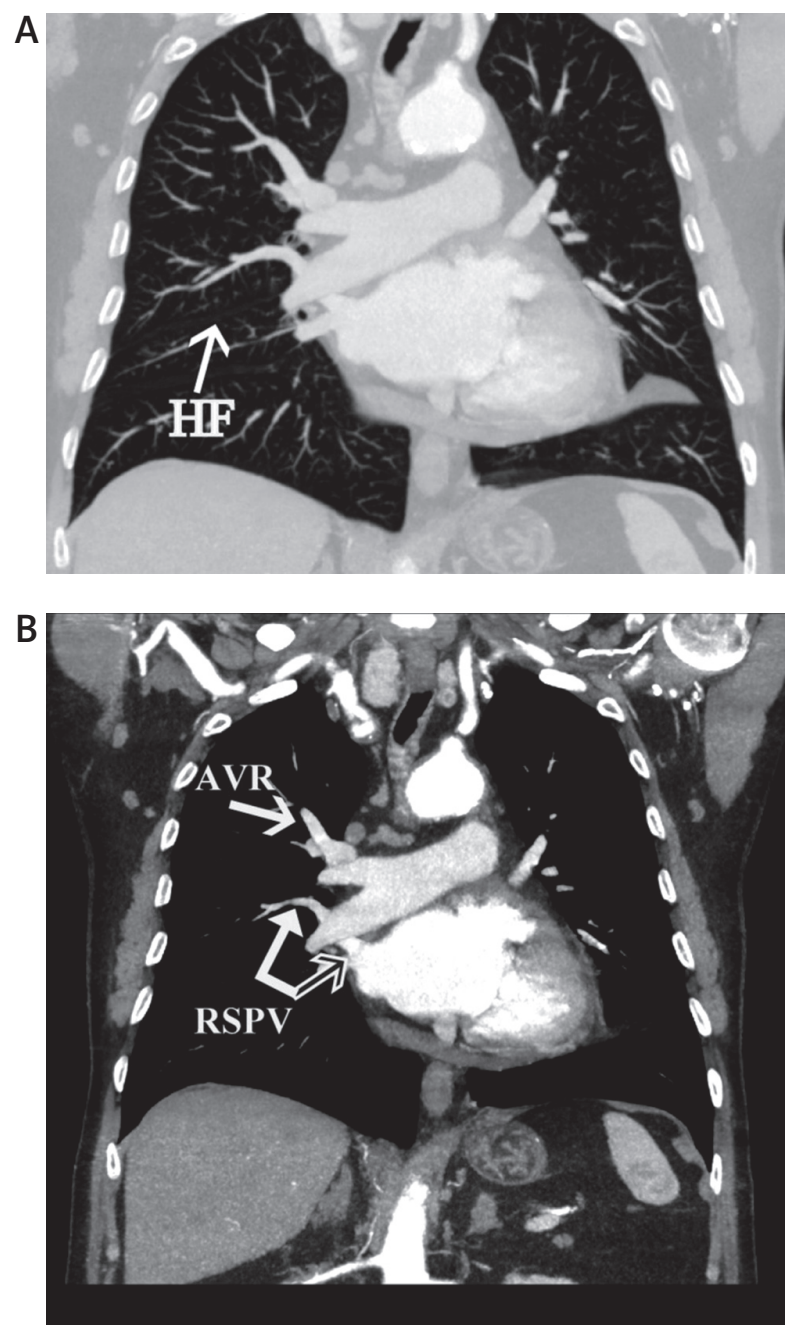

Fig. 3. A - Horizontal fissure (HF) separating the superior from the middle lobe of the right lung. B - Contrast-enhanced computed tomography showed anomalous drainage of the superior lobe of the right lung - a vein measuring $15 \mathrm{~mm}$ in diameter draining to the vena cava superior (AVR) and a right superior pulmonary vein measuring $8 \mathrm{~mm}$ in diameter running directly to the left atrium (RSPV) from the left internal mammary artery (LIMA) to the left anterior descending artery (LAD) was performed without complications. Chest CT showed an anomaly in the right upper pulmonary venous return. In accordance with standard practice, pulmonary angiography based on a chest CT was performed (Syngo via Siemens Healthcare Erlangen, Germany). Imaging with the $\mathrm{CT}$ angiography revealed that the first, main upper lobe venous drainage led to the vena cava superior by a vein measuring $15 \mathrm{~mm}$ in diameter (Fig. 2, 3 B, AVR) and a second vein measuring $8 \mathrm{~mm}$ in diameter running directly to the left atrium (Fig. 3 B, RSPV). Due to technical difficulties caused by the abnormal pulmonary vein position, a thoracotomy instead of video-assisted thoracic surgery was performed. Following that, a right upper lobectomy with mediastinal lymph node dissection was performed. The operation was complicated by atrial fibrillation - which was subsequently successfully treated pharmacologically.

In embryonic development PAPVR is the result of an incorrect connection between the common pulmonary vein and the splanchnic plexus. Clinical manifestations are usually not observed; however, these anatomical anomalies - if not reported before the surgery procedure - may lead to significant intra-operative complications. While the anomalous right-sided variation of the circumflex coronary artery did not directly influence the surgical procedure, the anomalous drainage from the lung was crucial for the choice of the surgical method of the right upper lobectomy. Video-assisted thoracic surgery (VATS) has become a routine surgical procedure for lobectomy, but anomalous variations of pulmonary vessels may mean that proceeding via a thoracotomy is more suitable in those cases. The reliable identification of anatomical vascular anomalies is a matter of paramount importance for a proper assessment of the best choice of method for therapeutic intervention.

\section{Disclosure}

Authors report no conflict of interest.

\section{References}

1. Milloy FJ, Wragg LE, Anson BJ. The pulmonary arterial supply to the upper lobe of the right lung. Surg Gynecol Obstet 1963; 116: 34-41.

2. Milloy FJ, Wragg LE, Anson BJ. The pulmonary arterial supply to the upper lobe of the left lung. Surg Gynecol Obstet 1968; 126: 811-824.

3. Magalhães SP, Moreno N, Loureiro M, Franca M, Reis F, Alvares S, Ribeiro M. Anomalous pulmonary venous connection: an underestimated entity. Rev Port Cardiol 2016; 35: 697.e1-697.

4. Yamanaka O, Hobbs RE. Coronary artery anomalies in 126,595 patients undergoing coronary arteriography. Cathet Cardiovasc Diagn 1990; 21: 28-40.

5. Gupta M. Partial anomalous pulmonary venous connection. Emedicine 2010.

6. Asai K, Urabe N, Yajima K, Suzuki K, Kazui T. Right upper lobe venous drainage posterior to the bronchus intermedius: preoperative identification by computed tomography. Ann Thorac Surg 2005; 79: 1866-1871. 